\title{
ANAESTHETIC TIME/DOSE CURVES. VII. EXPERIENCE WITH PENTAZOCINE*
}

\author{
G. R. GERULA, M.D., AND KEERI-Szanto, M.D. $\nmid$
}

Pentazocine is a Popular major analgesic drug. It differs from other drugs of similar potency by lack of addicting properties (although note la) and freedom from the red tape surrounding the administration of narcotics. Its side-effects (respiratory depression, inhibition of gastric motility, delirium) compare favorably with those of narcotics, both in incidence and severity.

In the hectic schedule of an operating theatre, the fact that one drug may be stored on the anaesthetic trolley while another has to be minutely accounted for represents - ceteris paribus - a significant convenience. It was, therefore, thought to be of interest to establish whether or not Pentazocine can be added to the drugs that would effectively supplement nitrous oxide - relaxant anaesthesia. In the course of these studies, we also expected to determine the drug's relative analgesic potency under actual clinical conditions and to investigate, again under actual clinical conditions, its respiratory depressant action.

\section{Matertal and Methods}

The investigations were carried out on 41 patients randomly assigned to the authors. They were selected only insofar that cases expected to last less than two hours, children under 10, and emergency surgery were excluded from the series. No patient was refused on account of poor physical condition. Premedication consisted of promethazine $0.7 \mathrm{mg}$ per $\mathrm{kg}$ and hyoscine $0.007 \mathrm{mg}$ per $\mathrm{kg}$ administered 90 minutes before arrival in the operating suite.

Pentazocine was diluted before induction to provide $2 \mathrm{mg}$ per $\mathrm{kg}$ in $20 \mathrm{ml}(0.1$ $\mathrm{mg}$ per $\mathrm{kg}$ per $\mathrm{ml}$ ). Anaesthesia was induced with $4 \mathrm{ml}$ of this mixture, followed by additional increments of $2 \mathrm{ml}$ a few minutes later if the initial dose did not result in abolition of the eyelid reflex. As soon as consciousness was lost, the patient was passively hyperventilated with a mixture of $\mathrm{N}_{2} \mathrm{O}-5 \mathrm{~L}$ per minute and $\mathrm{O}_{2}-2 \mathrm{~L}$ per minute and the trachea was intubated with the aid of Succinylcholine. Isokapnic controlled ventilation ${ }^{1}$ was continued throughout the procedure, the depth of anaesthesia was adjusted by 1-2 ml increments of the dilute Pentazocine solution and muscle relaxation was provided with d-tubo-curare as required. Curarisation was reversed at the end of surgery, the mouth was thoroughly

\footnotetext{
${ }^{*}$ From the Anaesthesia Department, Victoria Hospital and the Department of Anaesthesia, University of Western Ontario, London, Ontario. This study was supported in part by a grant from Winthrop Laboratories, Aurora, Ontario. Reprint requests should be addressed to the Anaesthesia Department, Victoria Hospital, London, Ontario. Presented at the American Therapeutic Society Meeting, Chicago, 20 June 1970. NOTE: Since the submission of this article, pentazocine has been re-classified by the FoD as Schedule G (controlled) drug.

$\nmid D r$. Gerula was Resident in Anaesthesia at Victoria Hospital, and Dr. Keeri-Szanto is Clinical Associate Professor in Anaesthesia, University of Western Ontario.
} 
suctioned and the endotracheal cuff was deflated. Extubation was left to the patients, who usually removed their tubes in the operating room or within minutes after their arrival in the recovery room. Nasal oxygen was administered to about half of the group and in four particularly poor-risk subjects, respirations continued to be mechanically assisted with room air for several hours. Sixty minutes after arrival in the recovery room, while the patients were breathing room air for at least fifteen minutes, arterial or capillary samples were drawn for blood gas analysis. The protocol was completed on the day following surgery when the patients were questioned about their subjective experience before and after the operation.

The drug requirements of each patient were determined by interpolation at $12.5,25,50,75,100,125,150,175,200,250,300$, and 350 minutes in units of $\mathrm{mg}$ per sq meter body surface, the data were averaged and the best-fitting mean time/dose curve was computed according to the equation formulated and validated previously. ${ }^{2}$

\section{Results}

Characteristics of the patient population, the type of surgery involved, data on muscle relaxants etc are set out in Table I.

TABLE 1

Composition of the Patiext-Popllation ix the Present Stedi

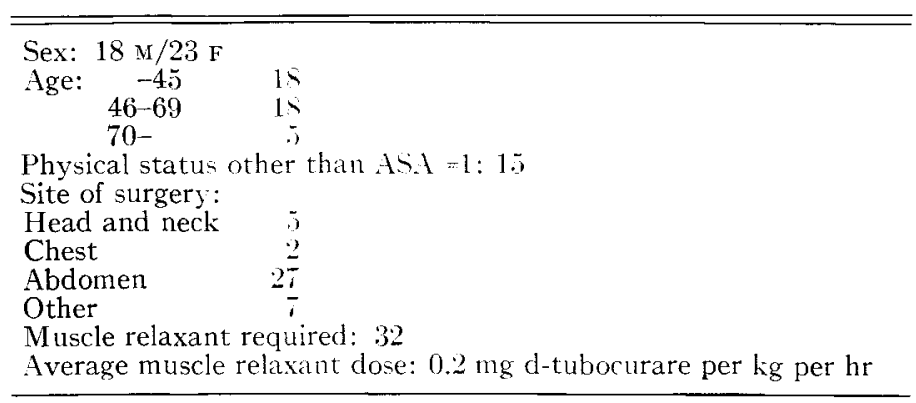

TABLE II

The Relative Potency of Pentazocine and Meperidine (DATA FROM REF. 13 FOR MEPERIDINE)

\begin{tabular}{rccccc}
\hline \hline & \multicolumn{3}{c}{ Pentazocine $(\mathrm{A})$} & \multicolumn{3}{c}{ Meperidine $(\mathrm{B})$} & \\
$t$ & $n$ & $M$ & & $n$ & $\mathrm{~B} / \mathrm{A}$ \\
\hline 12.5 & 41 & 20.6 & 23 & 37.4 & 1.86 \\
25 & 41 & 26.7 & 23 & 48.2 & 1.81 \\
50 & 41 & 31.6 & 23 & 60.6 & 1.92 \\
75 & 41 & 36.3 & 23 & 71.8 & 1.98 \\
100 & 36 & 38.7 & 22 & 81.1 & 2.09 \\
125 & 32 & 42.1 & 22 & 87.5 & 2.08 \\
150 & 28 & 45.2 & 22 & 93.0 & 2.06 \\
175 & 22 & 48.9 & 22 & 99.7 & 2.04 \\
200 & 13 & 51.5 & 19 & 106.7 & 2.07 \\
250 & 5 & 60.2 & 11 & 119.7 & 1.97 \\
300 & 3 & 61.5 & 8 & 120.1 & 1.95 \\
350 & 3 & 65.5 & 5 & 134.2 & 2.05 \\
& & & & & $1.99 \pm 0.09$ \\
\hline
\end{tabular}




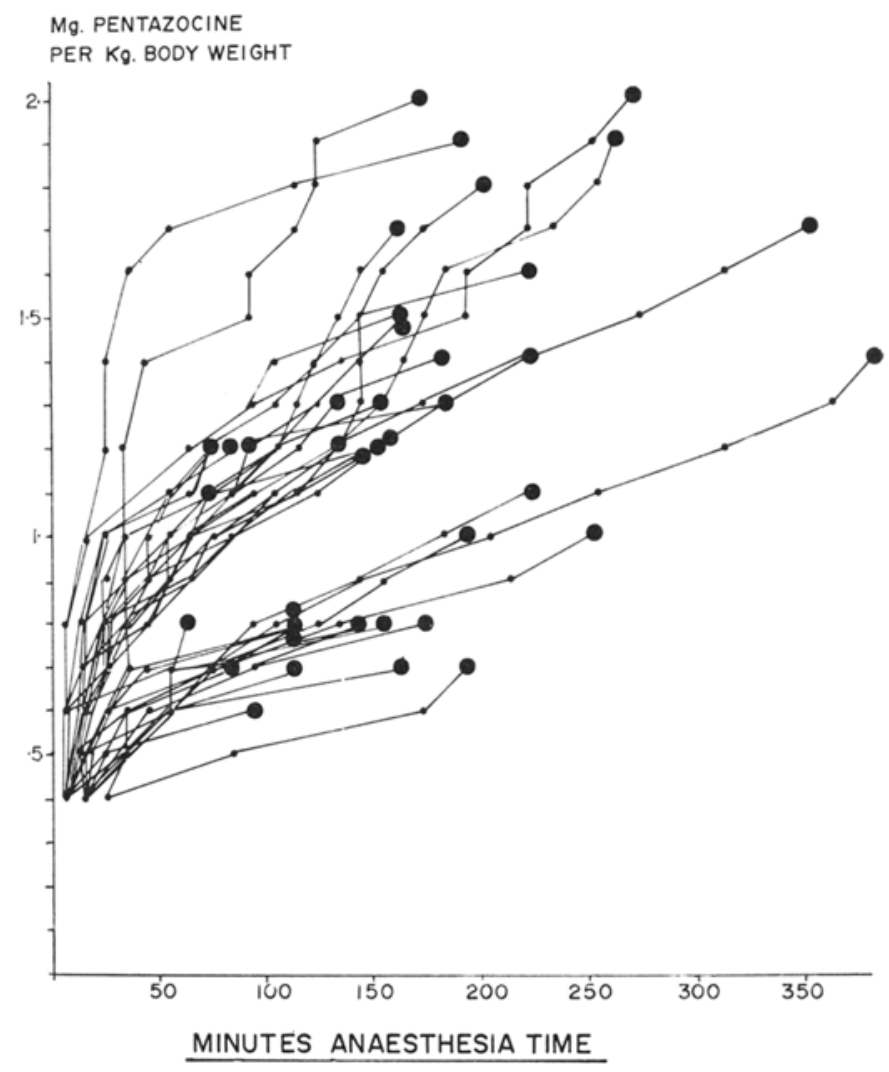

Frgure 1. Superimposed time/dose curves from 39 subjects. Circles indicate the end-point of individual runs. Note the discontinuity in the scatter of curves starting as early as 50 minutes after induction and splitting the group in 16-23 ratio.

The individual time/dose curves are presented in Figure 1, while Figure 2 shows the resulting mean time/dose curve.

Table II compares average drug requirements obtained under similar conditions with Pentazocine and Meperidine as well as the calculations leading to the establishment of the relative potency of the two agents.

Figure 3 contains the results of blood gas studies executed 60 minutes after the end of surgery.

\section{Discưssion}

Basic to this and similar investigations is the question of why one should bother at all with laboriously titrating his patients' responsiveness against the intensity of the surgical stimulus with intravenous agents when halogenated inhalation agents can provide the same result with much less trouble. The answer must start with defining "trouble." Let us say that trouble starts when one has no ready alternative to fall back on in providing safe and satisfactory anaesthesia for a patient and must hastily improvise some solution to a threatening situation. If this 


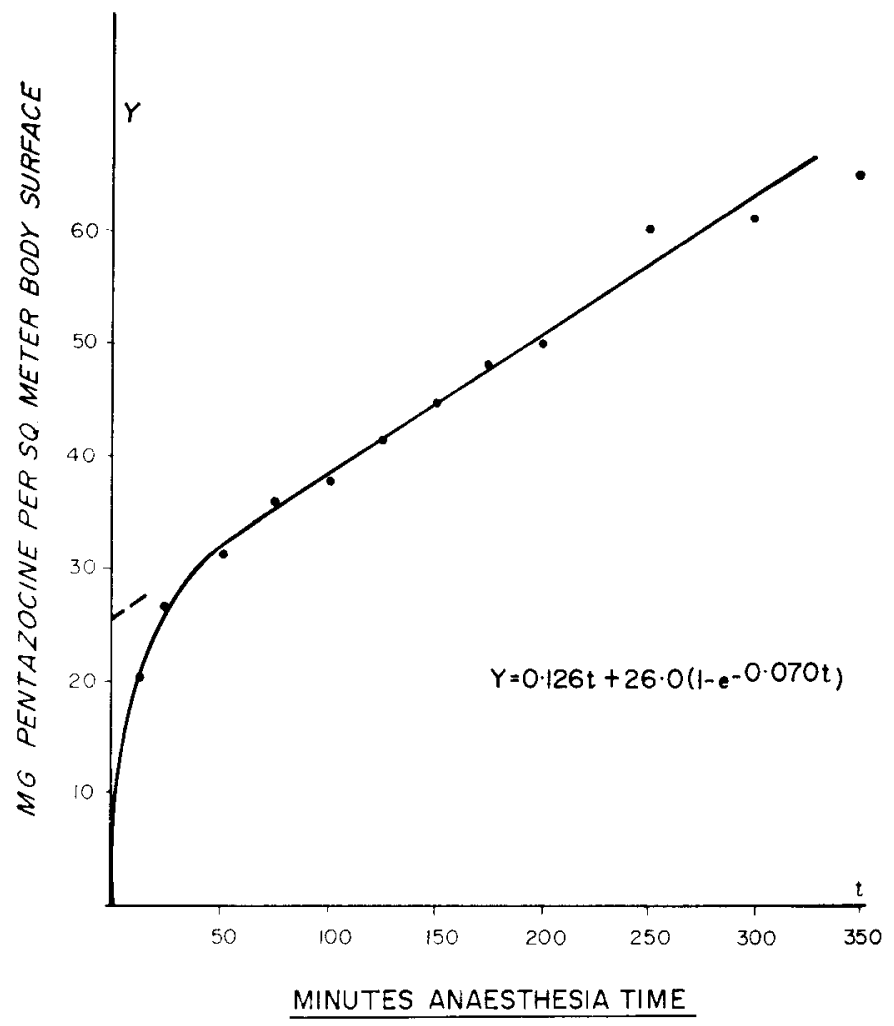

Frgure 2, The mean time/dose curve of Pentazocine. Values are transformed from $\mathrm{mg}$ per $\mathrm{kg}$ into $\mathrm{mg}$ per sq meter body surface in order to permit comparison with data from other anaesthetic adjuvants that have been established in these units.

occurs no more often than in one per cent of all patients, the anaesthetist will find himself in trouble about once a month - an unacceptable figure by today's standards, even if in nine out of ten cases he succeeds in extricating himself. There are formal contraindications to the use of halogenated agents in at least this percentage of the hospital population and the number of patients in whom a halogenated inhalation anaesthetic is permissible but not the first choice is probably twenty times greater. Ironically, the greatest threat to the future use of halogenated inhalation agents may well develop from the health hazard it represents not for the patients but for the operating room personnel. Be that as it may, there are good and sufficient reasons for continued inquiry into the potential of parenteral anaesthetics.

Table I confirms that Pentazocine has been put to a severe test, with respect to both the physical condition of the patients and the nature of their operations. The results were by and large satisfactory: induction was smooth, although slower than ideal in some cases. Haemodynamic disturbances were absent, recovery was prompt, leaving just the right amount of residual sedation in most patients. In our opinion, the Promethazine premedication played an important part in the successful outcome: preliminary studies with other types of premedication led to 


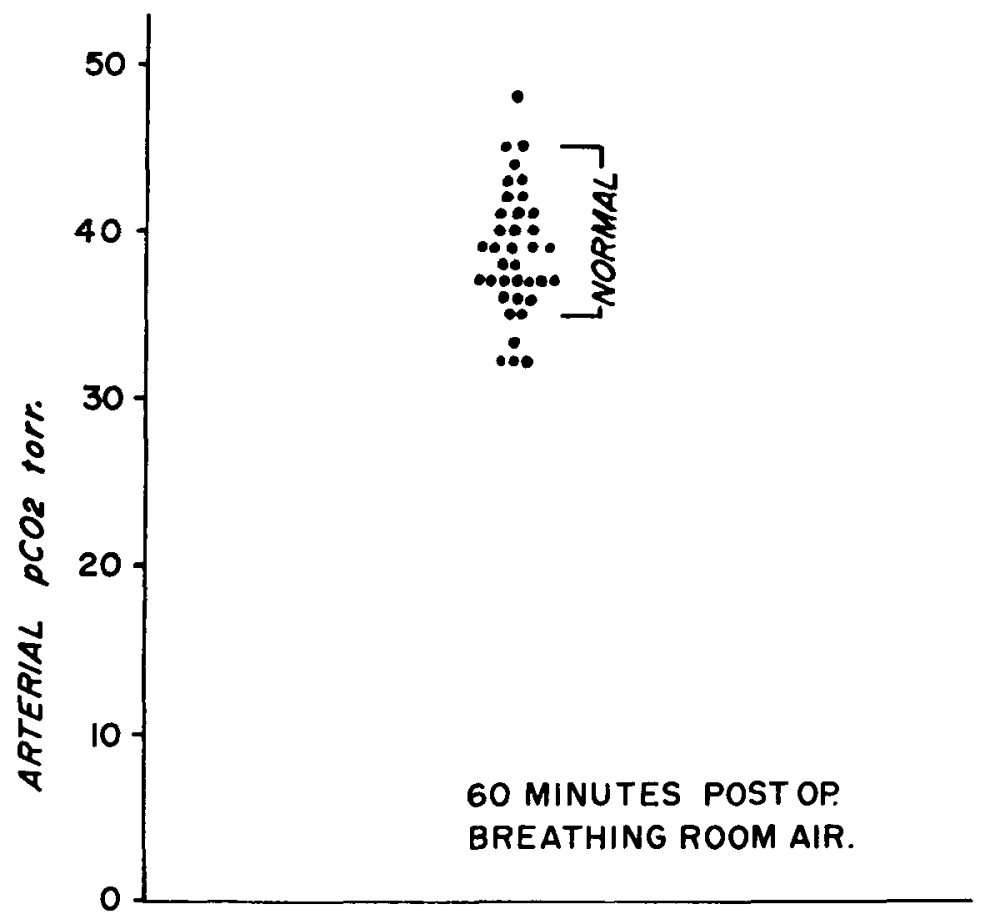

Figure 3. Arterial $\mathrm{PCO}_{2}$ values obtained 60 minutes after arrival in the Recovery Room. All patients breathing room air and all but four breathing spontaneously. In the four gravely ill subjects respirations were mechanically assisted with a Bird Ventilator.

much less satisfactory results. The only disadvantage that we encountered in this series was that we were unable to establish satisfactory anaesthesia in two subjects: one of these later confessed that he was a drug-addict while the difficulties in the other case remain unexplained. Both operations were uneventfully completed after halothane was added to the anaesthetic atmosphere. The number of patients operated on without any muscle relaxant and the amount of curare required in the remainder, support the contention that we were not dealing with profoundly curarised patients like those suggested by the Liverpool School of Anaesthetists. ${ }^{3}$ It is an interesting sidelight that one patient in this series complained of nightmares, while another vaguely recalled intubation.

It should be emphasized that the total amount of Pentazocine used in these subjects was very much less than the doses reported by others ${ }^{4,5}$ even though the other authors used thiobarbiturates for induction, which we did not. It is entirely possible that this is due to the fact that our patient population is different from the largely metropolitan populations on which the other results were based. We are finding that with certain agents, baseline data obtained some years ago in Montreal, are significantly higher than the drug requirements of the London hospital population. The interpretation of this finding and its implications will be discussed separately. ${ }^{6}$

The individual time/dose curves (Figure 1) show once more the peculiar distri- 
bution already described for other intravenous anaesthetics ${ }^{7}$ dividing the population into a high-consumption and low-consumption group. It will be seen that the division is cleaner than in previous series and that it involves more the slope of the curves (metabolisation rate) than their intercept with the abscissa (distribution space). The conclusion that the metabolisation rate of any drug shows step-wise differences within the hospital population has far-reaching consequences and requires further experimental support.

The mean time/dose curve (Figure 2) provides excellent fit to the experimental data with exception of the points at 300 and 350 minutes, each of which represents three observations only. The shape of the curve (the size of $\mathrm{k}$ and the ratio of $\mathrm{B}$ to A) conforms closely to the curves defined previously for other intravenous anaesthetics. In Table II the Pentazocine requirement in this series is compared with Meperidine requirement in an earlier study ${ }^{13}$ over a time-span from 12.5 to 350 minutes and making due allowance for decreasing sample size as the length of observation increases, we find that Pentazocine is 1.99 times as potent as Meperidine. This statement applies directly to anaesthesia only and is a minimum value since - as has been noted above - there is a good possibility that the drug requirements of a population sample drawn from a metropolitan hospital are inherently higher by about 40 per cent than that of a mixed urban-rural population we have observed in the present study. On the other hand, a method in which constant blood levels are maintained over prolonged periods, observations are made continuously and the end-point is defined in terms of wound pain rather than experimental pain or even more remote parameters should provide a more reliable comparison between the action of two analgesic agents. The methodological difficulties in this type of study are best demonstrated by the fact that estimates of the relative potency of Pentazocine vary by a factor as large as 3.7.5,8,9 Our own estimate lies well within but towards the lower end of the spectrum.

Dobkin and associates recently stated that Pentazocine was unsuitable in their hands to supplement $\mathrm{N}_{2} \mathrm{O}$-relaxant anaesthesia. ${ }^{10}$ Their patient material appears to be comparable to ours and it is remarkable that in spite of using twice as much Pentazocine, on the average, than we did plus thiopental in half of their patients, they were unable to achieve satisfactory operative and post-operative conditions. The explanation must lie in (1) our use of promethazine for premedication, (2) differences in the state of enzyme activation between the two hospital populations ${ }^{6}$ and, (3) wastage of medication caused by using a few large increments instead of repeated small ones ${ }^{12}$ - in our study the usual increments worked out to six to seven $\mathrm{mg}$ instead of thirty.

The data in Figure 3 point out an important and dangerous fallacy in clinical pharmacology. The conventional test for respiratory depression consists of administering the drug to healthy volunteers and measuring changes in the respiratory center's responsiveness during the ensuing hours. ${ }^{11}$ This model does not reflect the actual clinical events on several accounts: The clinical subjects frequently have respiratory disease, they receive more than one dose of the drug and they are under continuous stimulation from the surgical wound. It is, therefore, reassuring to learn that in a population that included many poor-risk 
patients, as well as operations involving the thorax and upper abdomen, satisfactory analgesia was routinely achieved while serious respiratory depression $\left(\mathrm{PCO}_{2}\right.$ $>50 \mathrm{~mm} \mathrm{Hg})$ was not seen at all and mild depression $\left(\mathrm{PCO}_{2}>45 \mathrm{~mm} \mathrm{Hg}\right)$ was seen only occasionally at the moment when such changes would be at their peak. Seventeen of the forty-one subjects were linked to a patient-activated motor syringe for pain relief and four of these received their first injection by the time blood gases were taken. Since some of our patients received considerably more Pentazocine than the volunteers in the cited study, we feel justified to conclude that under clinical conditions our data have over-riding validity and that in the presence of pain, judiciously administered Penazocine produces analgesia without significant respiratory depression. Whether or not this statement can be extended to cover other narcotics as well requires further study. More knowledge in this field is urgently needed because the current methods of postoperative pain relief are fully effective only in the greater half of patients subjected to major surgery. Almost a quarter of such patients experience distressing episodes of postoperative pain $^{12}$ in the name of "avoiding narcotic depression."

In conclusion, Pentazocine has proven itself a feasible alternative to intravenous narcotics for the supplementation of nitrous oxide relaxant anaesthesia, particularly when combined with Promethazine-Scopolamine premedication. It is superior to narcotics in its lack of addiction properties and freedom from the formalities of narcotic prescriptions. In the setting of these investigations it was found to be at least twice as potent as Meperidine, and it was free of respiratory depressant action in doses that provided satisfactory analgesia.

\section{SUMMARY}

Rigidly standardised nitrous oxide relaxant anaesthesia was supplemented in 41 subjects by $0.1 \mathrm{mg}$ per $\mathrm{kg}$ increments of intravenous Pentazocine for a variety of extensive major operations. Satisfactory anaesthesia was achieved in 39 patients. Individual anaesthetic time/dose curves were recorded for each patient: these revealed a sharp division into a high- and low-consumption group. Comparison of the mean time/dose curve with similar curves obtained earlier for other drugs, indicated that Pentazocine was at least twice as potent as Meperidine in this application.

Blood gas studies conducted one hour after the end of surgery showed that in the presence of pain, judicious doses of Pentazocine will provide adequate analgesia without respiratory depression even in poor-risk individuals.

\section{RÉSUMÉ}

Au cours d'une variété d'opérations extensives majeures, nous avons complété une anesthésie au protoxyde d'azote et myorésolutifs chez 41 sujets avec de la Pentazocine par voie endoveineuse à la dose $0.1 \mathrm{mg} / \mathrm{kilo}$. Nous avons obtenu une anesthésie satisfaisante chez 39 malades. Pour chacun des malades, nous avons fait une courbe anesthésique individuelle durée/dose: ces courbes ont établi une division marquée entre un groupe à haute consommation et un groupe à basse 
consommation. Dans cette application spécifique, la comparaison de la courbe moyenne durée/dose avec des courbes similaires obtenues antérieurement avec d'autres médicaments, laisse croire que la Pentazocine était au moins deux fois plus puissante que la mépéridine. Des études des gaz sanguins pratiquées une heure après la fin de la chirurgie ont montré que, chez le malade souffrant, des doses judicieuses de Pentazocine vont procurer une analgésie adéquate sans dépression respiratoire mème chez les mauvais risques.

\section{REFERENCES}

1. KeERI-SZANTo, M. Isokapnic Ventilation: Report on the Equipment and First Results. Anes. Analg. Curr. Res. 49: 406-412 (1970).

1. (a) Jasinski, D. R.; Martin, W. R.; \& Hoeldtke, R. D. Effects of Short- and Long-Term Administration of Pentazocine in Man. Clin. Pharm. Therap. 11: 385-403 (1970).

2. Keeri-Szanto, M. Drug-Consumption During Thiopentone-Nitrous Oxide-Relaxant Anaesthesia: The Preparation and Interpretation of Time/Dose Curves. Br. J. Anaesth. 32: 415-423 (1960).

3. Geddes, I. C.; \& Gray, T. C. Lancet 11: 4-6 (1959).

4. Ahlgren, E. W.; \& Stephen, C. R. Laboratory and Clinical Experience with a New Analgesic: Pentazocine. Anes. Analg. Curr. Res. 45: 673-682 (1966).

5. BauER, R. O. Unpublished data.

6. Keeri-Szanto, M.; \& Pomeroy, J. A. Intravenous anaesthetic requirements, enzyme induction, and atmospheric pollution: A causal correlation? Proc. A.S.A. Annual Meeting, New York, 1970.

7. Keeri-Szanto, M. \& Leduc, C. Anesthetic Time/Dose Curves. Iv. The Influence of Respiratory Parameters upon Intravenous Drug Requirements during Surgical Procedures. Anesthesiology. 23: 231-237 (1962).

8. Erb, H. A Comparison of the Analgesic Effectiveness of Pentazocine and Pethidine in Postoperative Pain. Gynaecologia. 162: 275-278 (1966).

9. Dyrberg, V.; Henningsen, P.; \& Johansen, S. H. The Respiratory Effects of Pentazocine. Acta. Anaesth. Scand, 11: 7-84 (1966).

10. Dobkun, A. B.; Israel, J. S.; \& Preloch, Pauline A. The Metabolic Response to Pentazocine as a Supplement to Balanced Anaesthesia for Major Abdominal Surgery. Canad. Anaesth. Soc. J. 17: 485-494 (1970).

11. Belville, J. W.; \& Green, Jean The Respiratory and Subjective Effects of Pentazocine. Clin. Pharm. Therap. 6: 152-159 (1965).

12. Keeri-Szanto, M.; \& Nash, F. C. Anesthetic Time/Dose Curves. Ix. Precision in Postoperative Pain Relief. Proc. Royal Coll. Phys. Surg. Can., Annual Meeting, Ottawa, 1971.

13. Keera-Szanto, M. Anesthetic Time/Dose Curves. in. The Limiting Factor in the Utilization of Intravenous Anesthetics during Surgical Operations. Clin. Pharm. Therap. 2: 45-50 (1961). 